\title{
Brief study on Practices of Arabic Language in Sri Lanka
}

\author{
Nagoor Gafoordeen ${ }^{1}$, Zamri Arifin ${ }^{2}$, Kasheh Abu Bakar ${ }^{3}$ \\ 1, 3 (Department of Arabic and Islamic Civilization, Faculty of Islamic studies, \\ Universiti Kebangsaan Malaysia, Malaysia)
}

\begin{abstract}
This paper studies the history of Arabic language culture among the Muslims of Sri Lanka since $9^{\text {th }}$ A.C. The Arab merchants' relationship with Sri Lankan empire has become a major turning point for the Arabic verbal communication development in early period. Before the colonial era, Arabic language was commonly used, which lead to the establishment of institutes for Arabic language teaching and learning even after the independence. Today there are five types of institutions offering Arabic language courses in Sri-Lanka. The Government schools conduct two types of examination certification in Arabic language subjects. While Madrasas (Religious base schools) offer eight years sharia certificate courses in Arabic language, government established universities offer such courses at degree level. The Jamia Naleemia, a private university also offers degree courses in Arabic Language. However, with all these establishments, language skills among the students specific are very much inadequate. Lack of developed Arabic Language curriculum, teaching material, teacher capacity and good learning environment are some of the reasons hindering the progress. The descriptive analytical study results suggest that the language curriculum and human resource development should be the main focus so as to improve the students' language skills development for them to be in Arabic language as a foreign language. This would be a qualified product toward institution as well as country contribution.
\end{abstract}

Key words: Arabic language, Institutions, learning, Sri Lanka, Teaching.

\section{Introduction}

Arabic is a semantic language spoken by 441 million native speakers, and a further 250 million nonnative speakers, in nearly twenty countries in the Middle East and North Africa. There is a standard form of Arabic, Modern Standard Arabic (MSA), which is based on the language of the Holy Quran, Classical Arabic, and is used as the educated Arabic speakers from different regions, as well as the main language of the media and films (Karin C, 2005). The contemporary Arab world is characterized by a high degree of linguistic and cultural continuity. Arabic is the official language of all the members of the Arab League, from North Africa to the Arabian Gulf (Karin C, 2005). Although geography accounts for much of the diversity of regional vernaculars, a shared history, cultural background and religion act to unify Arab society and give it a profound sense of cohesion and identity.

The introduction of Arabic language, Islam and Islamic civilization and Arabic language in the curriculum of the national universities of Sri-Lanka as well as the establishment of department of Arabic and Islamic studies is a big step towards the re-invigoration/re-vitalization of the Arabic language in Sri-Lanka (NIE, 2009). These conditions enable Muslim students to learn Islam as a subject for General Examinations as well as follow a course in Islamic studies in the national universities (UGC, 2010). For the record, there are 749 Muslim Schools in Sri Lanka, and 205 madrasas registered under the Department of Muslim cultural affairs which provide Islamic education. The Islamic university in Beruwala (Jamiya Naleemiya) and Two State Universities offer first degree in Arabic and Islamic studies. Two other universities are offering General Degree programmes. Although, Government Teachers Training Colleges (GTTC) and Colleges of Education have been established to train the teachers for teaching Islam, and Arabic language at government schools (Ministry of Education, 2010). There is a Muslim Religious consultative Board appointed by the Ministry of Education to counsel the government on matters related to the teaching of Islam and Arabic in schools (Ministry of Education, 2010). The Muslim Unit of the Ministry of Education and the National Institute of Education (NIE) frequently conducts seminars for teachers of Arabic and Islamic studies (NIIE, 2009).

Over the last twenty years many countries have been moving towards free movement of supplies, services and people. These trends, repeatedly termed "globalization," have led government to review their plans for economic and social development. According to that, the objectives of Sri Lanka education policy is to enhance equitable access and quality of primary and secondary education to provide a foundation for the knowledge-based economic and social development of the country (Document Report, 2012), in addition, promoting life-long education and knowledge renewal through programs of formal and informal education and to promote the democratization of education (World Data: Education, 2010). 
As to the achievement of the above objectives, the Ministry of Education and Ministry of Higher Education of Sri Lanka considered reforming the language curriculum. The Curriculum Development Centre of Sri Lanka in collaboration with Asian Centre of Educational Innovation for Development (ACEID), National Institute of Education (NIE) and the Universities are involved in reforming the Curriculum (Ministry of Education, 2005).

Language curriculum is always different when compared to other curricula. The aim of designing Arabic Language curriculum is to investigate the teaching and learning techniques and design the lesson plans (I.S.P. Nation and John Macalister, 2010). Most of the decisions made on the subject of constraints, needs, principles, content and sequencing will only be circuitously noticed through the format and presentation of the lessons. But these decisions must be tested in lesson format otherwise, the work that has been done on these aspects of curriculum design will be wasted, and the course might not be useful for the students as what they are expecting.

Based on the necessity of this issue, this paper is try to find out the status of the Arabic language in the institutions of higher learning in Sri Lanka. In order to address the research questions for this study, the descriptive analytical paradigm was chosen to investigate the development and influential benefits of the Arabic language culture to the Sri Lankan communities. It also tries to identify the status of the language at institutional level. The documented reports, curriculum of the institutions and UGC Guide forms the instrument of the study.

\section{Background of the History}

Islam in Sri Lanka and the materialization of the Muslim society are inextricably interlinked with the Arab commercial activities in the Indian Ocean. Thus, a study of the Islamic history in Sri Lanka necessarily involves a study of the Arab sea faring in the Indian Ocean in the pre-Islamic and post-Islamic periods. As the early Arabs were connected to this island by their beautiful items of trade and serving as facilities for their resorts, a great number of them had settled down mainly in the ports and made the island as their home. It is likely then, that Arab settlers came to represent the heart of the Muslim community (Al-Baladhuri, 1935).

The religion of Islam and the Arabic language were the factors which are well-known as a miscellaneous cultural being. The Arab traders who came mostly from the Persian expanse - especially from Iraq to Sri Lanka and other countries in the Indian Ocean brought with them Islamic religion and the Arabic language. Muslims of Sri Lanka during this period seems to have had a very strong cultural link with Baghdad. This is definite by the discovery of Arabic inscription in Colombo. This inscription mentions about Khalid Bin Abu Baqaya who was sent to Sri Lanka by the Abbasside Khalifa of Baghdad about 300 A.H. / 940 A.D. in response to the demand by Sri Lankan Muslims for a religious educator (Sir, Johnson, A., 1827). Throughout the centuries, there had been an increased number of Arab Muslim settlements along the coastal belt of the island due to the flourishing viable activities between Sri Lanka and the Persian Gulf ports which is confirmed by the archaeological excavations at Manthai and most primitive ports of Sri Lanka (Sir, Johnson, A., 1827).

Many inscriptions written in Kufi letters from 9 to 11th centuries such as those of Mannar (Puliyantheevu, Vettiyamaruppu and Ellupitiya inscriptions) and Colombo established the permanency of Arab settlements. These inscriptions, revealed in the surrounding area of Fort Stenberg are evidences of Arab settlements in that town. It has been suggested that the area around Chapel Hill in the Trincomalee Dockyard used to be an Arab settlement (UNESCO, 1985). After independence, in order to safe guard, maintain and further their Islamic cultural identity, Muslims required the state to acknowledge the Muslim personnel law (Shukri, M.A.M. 1986). In the field of education, the establishments of Muslim schools are some of the privileges enjoyed by the Muslim community under all successive governments since independence (Mahroof M.M.M. 1986).

As a multi-racial country in an interdependent world, Sri Lanka is also affected by the global economic crisis. Employment situation in Sri Lanka necessitates the need for graduates to obtain employable skills including proficiency in a foreign language. The, Chairman of UGC- Sri Lanka stated that "The challenge before us is to increase access to higher education while improving the quality of education. The curriculum and courses we offer should contribute to the production of a skilled labour force that meets the demands of the new millennium." (Samaranayake, 2011). Therefore, the Arabic language curriculum should be reconsidered to enhance skilled ability productivity. For example, Malaysia is a country in the same region with Sri Lanka and motivates the students to learn foreign language. Malaysian universities provide language learning opportunities for students to be proficient in a third language. In addition, in Malaysia the third language help graduates not only to get access to the latest technology and information but also to get an added advantage in an increasingly multicultural and diverse work environment (Ainol Madziah, 2009). Nurul Huda (2009) analyzed the Arabic language teaching and communications errors among the Malaysian learners at International Islamic University of Malaysia (IIUM). She identified communication skills as the major set back among the students of Arabic 
Language. The curriculum reform should consider communication skills too. The methodoly of this study will be a guide to formulate a questionnaire on learning Arabic Language.

Subsequently, the literature acknowledges an excess of research in the understanding and practices of foreign language programmes and therefore more attention should be given to policies and practices of Arabic language at Universities in Sri Lanka. Special focus should be paid to planning and development of programmes based on the teaching methods and motivating students to learn Arabic language. In analyzing the numerous researches on the teaching and learning of Arabic language in Sri Lanka, Ameena Cassim (1994) analyzed the Arabic language syllabi of University of Peradeniya and suggested that the syllabus should be developed further to accommodate and enhance skill labour. However, she did not suggest the mechanisms of how to motivate the Arabic Language students. This study aimed to analyze the specific university syllabi before 1994 and the curriculum reform in several universities. Therefore, the study would be undertaken not to evaluate current situation of this university only, but also other universities in Sri Lanka offering Arabic language. Barie, M.S.A, (2000) studied about the contribution of Madrasas (Arabic colleges) for Sri Lankan Muslim community and he found that, there are immediate needs to develop the language skill ability among the Madrasa Students as a solution to reduce their job crisis in future. Munas, M.H.A, (2009) researched about the issues on teaching and learning Arabic language at the madrasas in Batticaloa district in Sri Lanka. He claimed that the eastern province Arabic colleges should think of building a network with madrasa in Batticaloa to overcome the problem of teaching Arabic language. The above two researches focused on structural teaching methods and the syllabi of Arabic colleges.

\section{Purpose of the Study}

The purpose of the study is to examine the status of the Arabic language in the institutions of higher learning in Sri Lanka. The following research question intend to guide this study: What is the trend of Arabic language instruction in institutions of higher learning in Sri Lanka?

\section{Methodology}

In order to address the research questions for this study, the descriptive analytical paradigm was chosen to investigate the development and influential benefits of the Arabic language culture to the Sri Lankan communities.

\section{Results}

Through the study, it could be identified that there are five types of Arabic language teaching institutions that are offering Arabic language courses through different curriculum.

\subsection{Arabic Colleges or Madrasa}

Teaching Arabic in Sri Lanka was started at Madrasa level in the early period of 1880 A.D. Madrasathul Makkiya was the founding institution for Sharia studies in Arabic and Tamil Languages, based on the governing of Mappilai Lebbe Alim in Southern province of Sri Lanka. At the movement, there are more than 205 Madrasas registered as Arabic Colleges (AC). Most of Them are following the Dar's - e- Nizami syllabusIndia Madrasa System in teaching and management. These colleges are private intuitions registered under the act of Muslim cultural affairs of Sri Lanka. However, there are significant developments that occurred in the AC system after the independence (Abdul Barie, 1999). Even though, the teaching and learning of Arabic language in these institutions are under arguments, the syllabus of AC does not reform in long periods. The language text books do not enclose any teaching area, methodology, evaluation, etc. The Arabic language teachers of AC have not trained to teach Arabic language (Abdul Nasar, 1999). Teaching environment is not suitable for a range of aptitude of students' in a class. The All Ceylon Jammiathul Ulama is considering adopting common syllabus and teacher guide for Arabic Colleges, but has not seen the light of the day yet.

\subsection{Government Schools}

The National Institution of Education (NIE) introduced Arabic language (AL) in school syllabus in three categories. First category is two years component syllabus for grade eight to Nine students as elementary Arabic language. Second category is two years General Certificate Examination of Ordinary Level (G.C.E.O/L) based syllabus. It includes two types of subjects; Arabic language and Arabic literature for (G.C.E.O/L) students. Last Category is a two years General Certificate Examination of Advanced Level (G.C.E.A/L) University admission based syllabus. Schools follow government recommended syllabus (NIE 2009). However it has been criticized that the syllabuses designed are religious based, not for the perspective of foreign language, although, "Al- Arabiyyah Ii nashien" the volume 4, 5 is the text book recommended by the SriLankan curriculum development department. If the texts are designed for non Arabic speaking pupil, the 
contents of the books should be reconsidered as it is only suitable for the Sri Lankan environment. Therefore, the Non- Muslims will not be bothered while they study Japanese, French and Latin languages, etc.

\subsection{Arabic Language at Tertiary Educational Institutions}

The University Grants Commission (UGC) of Sri Lanka is the organization responsible for the establishment of faculties and departments that offer degrees programmes in Arabic Language and Islamic studies. Accordingly, four universities are conducting undergraduate programs at present and only the University of Peradeniya conducts the postgraduate programs.

Fig 1: Arabic Language Courses Selected By Undergraduate Students

\begin{tabular}{lccc}
\hline \multicolumn{1}{c}{ University } & $2010 / 2011$ & $2009 / 2010$ & $2008 / 2009$ \\
\hline University of Peradeniya & 15 & 13 & 14 \\
Eastern University of Sri Lanka & 11 & 15 & 14 \\
University of Colombo & 02 & 04 & 03 \\
South Eastern University of Sri Lanka & 22 & 27 & 20 \\
\hline
\end{tabular}

\subsubsection{University of Peradeniya}

The department of Arabic was established in 1945 at the University of Ceylon as a department under the Faculty of oriental studies. Initially it runs only undergraduate program, but in 1956, a graduate MA program was introduced effered. In 1969 Islamic Civilization was introduced as a subject in the department. In 1972, when the university system was "reorganized", the Department of Arabic and Islamic Civilization was moved to the Vidyalankara campus of the University of Sri Lanka, at Kelaniya. In 1980 the department was relocated back to the University of Peradeniya. The department conducts General, Special, Postgraduate Degree in Arabic and Islamic Civilization. The medium of instruction of the courses are English, Sinhala and Tamil (Hand book, 2000). However Arabic language wasn't involved in the teaching process.

The Arabic language curriculum of the department was reformed five times, but it does not include plans to increase the number of student intakes. The teaching material, language teaching methods, evaluation methods, and recommended reference materials are the basic issues that still needed urgent attention.

\subsubsection{Eastern University of Sri Lanka}

The Eastern University, Sri Lanka, was established on the 1st of October 1986. The Faculty of Cultural Studies contains the Department of Arabic and Islamic studies. Arabic language (AL) was made a compulsory subject for special intake students. The curriculum of AL was reformed two times and the department also did not include methodological curriculum and teacher training.

\subsubsection{University of Colombo}

In the University of Colombo, after a lapse of 15 years, teaching of Arabic and Islamic civilization subjects was re-introduced in 1995 based on the recommendation of the University Grant Commission. By introducing the courses of studies, the university succeeded in minimizing one of the grievances of the Tamil medium students. The Arabic language syllabus was then designed for beginners and it included the course contents, outcomes and recommended references. But, it does not include the teaching evaluation methods as well as teachers' guide.

\subsubsection{South Eastern University of Sri Lanka}

In October 2005, the Faculty of Islamic Studies and Arabic Language was established with 50 students for the Academic Year 2005/2006 going by the admission policy of University grants Commission. This is the only faculty of a university in Sri-Lanka that enjoys good facilities that no other faculty enjoys since its establishment (Hand book, 2008). The Department of Arabic Language offers special degree courses in Arabic language, Arabic literature and Arabic linguistic as well as Arabic translation. It developed advanced curriculum, but, there are shortcomings on designing courses for beginners. The Arabic language teachers were not trained on the principal subjects. The faculty has taken leading role in developing the program through improving human resources capacity.

\subsection{Jamia Naleemia (Institution as private shariea institution)}

Jamia Naleemia was established in 1973 by Al- Hajj M.A.M. Naleem. The main objective of the institution is to produce Islamic intellectuals for Muslim world collaboration (Al-Jamia, 2004). This institution designed a seven years program which was approved by the International Islamic University of Islamabad. The Arabic language curriculum is more satisfying than the curriculum of the Arabic colleges. The instructors for 
Arabic language came from Egypt on contract basis and the graduates of the institutions are working in embassies of Arab countries in Sri-Lanka as well as abroad.

\subsection{Arabic Language at Other Institutions}

The cultural section of embassies from Arab countries organizes Arabic language courses for students who are interested in continuing with their study in Arab countries. The world Islamic call society of Libya, Embassy of Saudi Arabia and Egypt Cultural centers of these embassies do organize short term courses for the students who are willing to proceed for higher studies in universities and colleges in their respective countries. These courses are taught by the Arab native instructors. Consequently, very little percentage of the students strives to improve on their Arabic language ability. As non governmental organizations, the Islamic movements and cultural federations do conduct such lessons without proper course guidelines.

Sri Lanka is a multi-racial country in an interdependent world affected by the global economic crisis. Employment situation in Sri Lanka necessitates the need for graduates to obtain employable skills including proficiency in a foreign language. The, Chairman of UGC- Sri Lanka was quoted as saying; "The challenge we are facing is to increase access to higher education while improving the quality of education. The curriculum and courses we offer should contribute to the production of a skilled labour force which matches the demands of the new millennium"(Samaranayake,2010). Therefore, Arabic language curriculum should be reconsidered in order to improve the students' achievement in practicing at all institutions. The Universities must take leading role in this to develop the language. For Example, Malaysia a country with similar program like that of Sri Lanka, and it also motivates its students to learn at least one foreign language where Malaysian universities are expected to provide learning opportunities for students to be proficient in a third language (Ainol Madziah Zubairi, Isarji Hj Sarudin 2009). In addition, the third language is to benefit the graduates not only for getting access to the latest technology and information, but also getting more leverage in an increasingly multicultural and diverse work environment.

\section{Conclusions and Recommendations}

The Arabic curriculum of institutions in Sri Lanka lack systematic progression. It neither matches students' ability to learn, nor takes consideration into the happiness of each phase of age in choosing literature. Arabic language teachers are still adopting approaches based on memorization which in turn discourages the students' motivation in learning the language and decrease their potentials in learning new expressions and be creative towards the language. Memorizing and reciting without having the chance to reword, explain and analyze in their own words hinders the students from learning new vocabulary and the system of the language. At the same time these flaws limit the correct usage of terms.

The student-teacher relationship in such an approach prevents the students from asking questions as to their challenges in expressing themselves. As a result, they tend to learn without really understanding the meanings. Limited vocabulary usage to theoretical explanation without linking it to real-life situations is another factor which contributes to students' poor performance on lexis. Additionally, the students found this approach boring and therefore easily lose focus.

Subsequently, the literature acknowledges an excess of research in the understanding and practices of foreign language programs. More information is required on the policies and practices of Arabic language at Universities in Sri Lanka, especially in terms of planning and developing programs based on teaching methods and motivating students towards Arabic language learning.

\section{References}

[1] H. S. Ainol Madziah Zubairi, Motivation to Learn a Foreign Language in Malaysia. GEMA Online Journal of Language Studies, 9(2), 2009,75-84.

[2] S. A. Johnstone, Archaeological Evidence of Early Arabs in Ceylon. Sri Lanka: Moor's Islamic Cultural Home, Royal Asiatic Society of Great Britain and Ireland. 1882, 537.

[3] G. Samaranayake, The global higher education system and the knowledge hub in Sri Lanka. Paper presented at the 27th Annual General Meeting of the Sri Lanka Quantity Surveyors Association, 2011.

[4] Al-Baladhuri, Futuh- al-Buldan( Cairo: Cairo, 1935).

[5] W. John, The Excavations at Mantai- Ancient Ceylon (Vol. 01, Colombo, 1990).

[6] M. M. M. Mahroof, The Ambiance of Mosque in An Ethnological Survey of Muslims of Sri Lanka.( Colombo, 1986)

[7] A. Nasar, Madarisul Arabiya Bainal Mazi Wal Hazir,Wal Mustaqil. Akurana (Nadwathu Rahmaniyeen, Sri Lanka: Akurana., 2009).

[8] N. H. B. Othman, Curriculum of teaching Arabic to non-Arabic speakers (Malaysia: International Islamic University Malaysia, 2009).

[9] SEUSL. University Handbook (Sri Lanka: South Eastern University of Sri Lanka, 2008).

[10] M. A. M. Shukri, Muslims of Sri Lanka (Sri Lanka: Jamia Naleemia,1986).

[11] UPDN, University Handbook (Sri Lanka: University of Peradeniya.2000)

[12] UGC, University admission Guide (Sri Lanka: University Grant Commission. 2010). 
[13] M. S. A. Barie, The role of Arabic Madrasas (Institutions) in the Socio-cultural Renaissance of the Sri lankan Muslims, Master of Philosophy Diss., University of Peradeniya, Sri Lanka,. M.Phil. unpublished thesis, 2000.

[14] A.Cassim, Proposals for amendment on teaching Arabic at University of Peradeniya. (Arabic), Master diss., International Islamic University of Malaysia,Malaysia, MA. Unpublished thesis, 1994.

[15] H. M.Munas, Teaching Arabic at the madrasas in Sri Lanka, Master diss., Universiti Kebagnsaan Malaysia,Malaysia, M.A., 2009.

[16] NIE. Arabu Moly Padathittam (Sri Lanka: National Institution of Education, 2010).

[17] H. Aturupane, Document Type Implementation Status and Results Report (2012/06/24).

[18] UNESCO, Sri Lanka Cultural Triangle Project (1985).

[19] UNESCO. 1985. Sri Lanka Cultural Triangle Project (C.D.N. of 07-08, 1985). 